\title{
Random utility approach to re-designing the passengers interchange node
}

\author{
P. Zito \& G. Salvo \\ Transport Engineering Department, University of Palermo, Italy
}

\begin{abstract}
The passengers interchange node is a complex infrastructure where the user can choose among different modal options for his/her trip. These transport infrastructures have various terminals (car park, bus stop, metro, light rail, railway, extra-urban and sub urban bus and so on). The passengers inside the interchange node have to reach these terminals, often walking with luggage and for long distances. We calibrated a discrete choice model taking into account attributes that are able to explain passenger behaviour by observed flows and the generalized least squares technique. Furthermore, an ex ante/ex post analysis was carried out in order to design and evaluate measures for incentive modal integration, improving perceived quality and transfer facilities in the walking path.
\end{abstract}

Keywords: interchange node, random utility, discrete choice model.

\section{Introduction}

In recent years, the growth of metropolitan areas has caused a significant increase of the residential population in sub urban areas (urban sprawl). Long distances between residential areas and service/facility centres, usually located in the Central Business District (CBD), and the large use of private cars in respect to transit, cause congestion (in some corridors of the road network), lost time, pollution, noise and in general a low quality of life for citizens. In such a context, the passengers interchange node plays a crucial role in an integrated multimodal transport system. The passengers interchange node is a complex infrastructure, where the user can choose among different modal options for his/her trip. These transport infrastructures have various terminals (car park, bus stop, metro, light rail, railway, extra-urban and sub urban bus and so on). The passengers inside 
the interchange node have to reach these terminals, often walking with luggage and for long distances.

Delle Site et al. [1] used an optimization problem, taking into account management, build and users costs, by minimization of a whole objective cost function. Nevertheless, the authors bounded the analysis only to pedestrian aisles of the interchange node, along which automated people mover systems can be installed. Parizi and Braaksma [2] analysed the whole interchange node with the micro simulation approach. The authors carried out an optimization process from the viewpoint of maintenance and management costs of the interchange node, divided into sets of facilities (people movers, lifts, shops, waiting lounges and so on), given a whole passenger demand and a maximum amount of available resources. In literature, many studies concern pedestrian mobility within airports, but the methodology can be extended to any passenger interchange node. De Barros et al. $[3,4]$ used a utility function approach to determine the optimal configuration of a modal interchange node. Next, the same author [5] evaluated the service level for a passenger interchange node, taking into account other facilities with the operative characteristics of an interchange node. Correia et al. [6] showed an overall index for the evaluation of service level related to operative components of an interchange node.

This paper aims to realize a framework for the passengers interchange node by the random utility approach in order to analyze and understand:

- which attributes are significant that can explain the passenger behaviour;

- which measures the designer can adopt to reduce transfer disutility of passengers.

For this purpose a survey on passenger flows was carried out inside an interchange node in Palermo (Giulio Cesare Square). We calibrated a discrete choice model taking into account attributes that are able to explain the passenger behaviour by observed flows and the generalized least squares technique. Furthermore, an ex ante/ex post analysis was carried out in order to design and evaluate measures for incentive modal integration, improved perceived quality and transfer facilities in the walking path.

\section{Characteristics of the study area}

Palermo is the main Sicilian city, with an area of $158 \mathrm{~km}$ squared and a population of about 700.000 inhabitants, with a large historical centre (about 2,7 $\mathrm{km}$ squared). This area is the centre of the main directional and administrative functions of the island. The mobility system inside the metropolitan area of Palermo is characterized by a strong lack of railways transport systems, the lack of an efficient public transport system and the lack of suitable parking areas. The urban railway system operating in Palermo has been derived from the traditional railway infrastructures crossing the town. In particular, the railway system connects the Central Railway Station, the town and airport (about $30 \mathrm{~km}$ away from Palermo). The main bound of the actual urban railway system is single track. This implies a maximum frequency at the stations equal to 2 trains per 
hour. Another bound is the decentralised position of the railway stations in respect to the main activities in the city. These characteristics penalize the citizen in the railway mode choice. Public transport by bus covers almost all areas of the city, but only a few lines run in reserved lanes. Thus, performances are influenced by congestion of private mobility causing inefficiency in the level of service (travel and waiting time and scheduling). Furthermore, the city has few parking areas and has no parking area of interchange with other transport modes.

In the metropolitan area, the mass rapid transit system will be performed by a fundamental rail transport network composed by light rail, through railway and underground; and a feeder tram system realized by three tram lines.

Figure 1 shows the mass rapid transit system in the metropolitan area of Palermo between Punta Raisi Airport and Roccella. The realization of an integrated mass rapid transit system with interchange nodes and stations will allows to improve trips inside the metropolitan area, by using interchange parking areas and park \& ride policy (as such as Roccella parking area).

The modal interchange node chosen for the analysis is Giulio Cesare Square's one (identified by Palermo Centrale). In the study area various transport passenger terminals are situated (as such: railway station, metro, urban bus stops, regional service bus stop and three parking areas). A survey was carried out aiming to indentify the characteristics of the node in the peak hour $8,00-9,00$. This observed patterns were: pedestrian flows among various transport terminals, length of pedestrian paths, parameters of traffic lights (cycle time, split, offset), widths of roads, road parking supply, illegal parking, frequency of bus lines, mean delay times at the departures and arrivals terminal, ongoing and outgoing vehicles flows, horizontal and vertical signs, positions of bus stops, etc. For the analysis of parking supply, three parking areas were considered close to the study are situated in Giulio Cesare Square, Torino Street and Marinuzzi Street.

Figure 2 highlights the position of various terminals (identified by a number as follows: 1 railway station, 2, 3, 4 urban bus stops, 5 regional service bus stop, 6, 7, 8 parking areas); whereas table 1 and 2 show the paths' lengths (expressed in $\mathrm{m}$ ) and the mobility demand (O/D matrix) among terminals respectively.

\section{Discrete choice model}

The calibrated distribution model is a multinomial logit, whose mathematical formulation is as follows:

$$
p_{i, j}(b)=\frac{e^{V_{i, j}}}{\sum_{j=1}^{N} e^{V_{i, j}}}
$$

where $p_{i j}$ is the choice probability, $N$ the number of pedestrian paths, $b$ the coefficients' vector, $V_{i j}$ the systematic utility expressed by $V_{i, j}=\sum b_{i, j} X_{i, j}$, and $X_{i j}$ is the attributes of pedestrian paths. This model was calibrated by observed flows and generalized least squares technique. The generalized least squares estimator minimizes the following expression: 


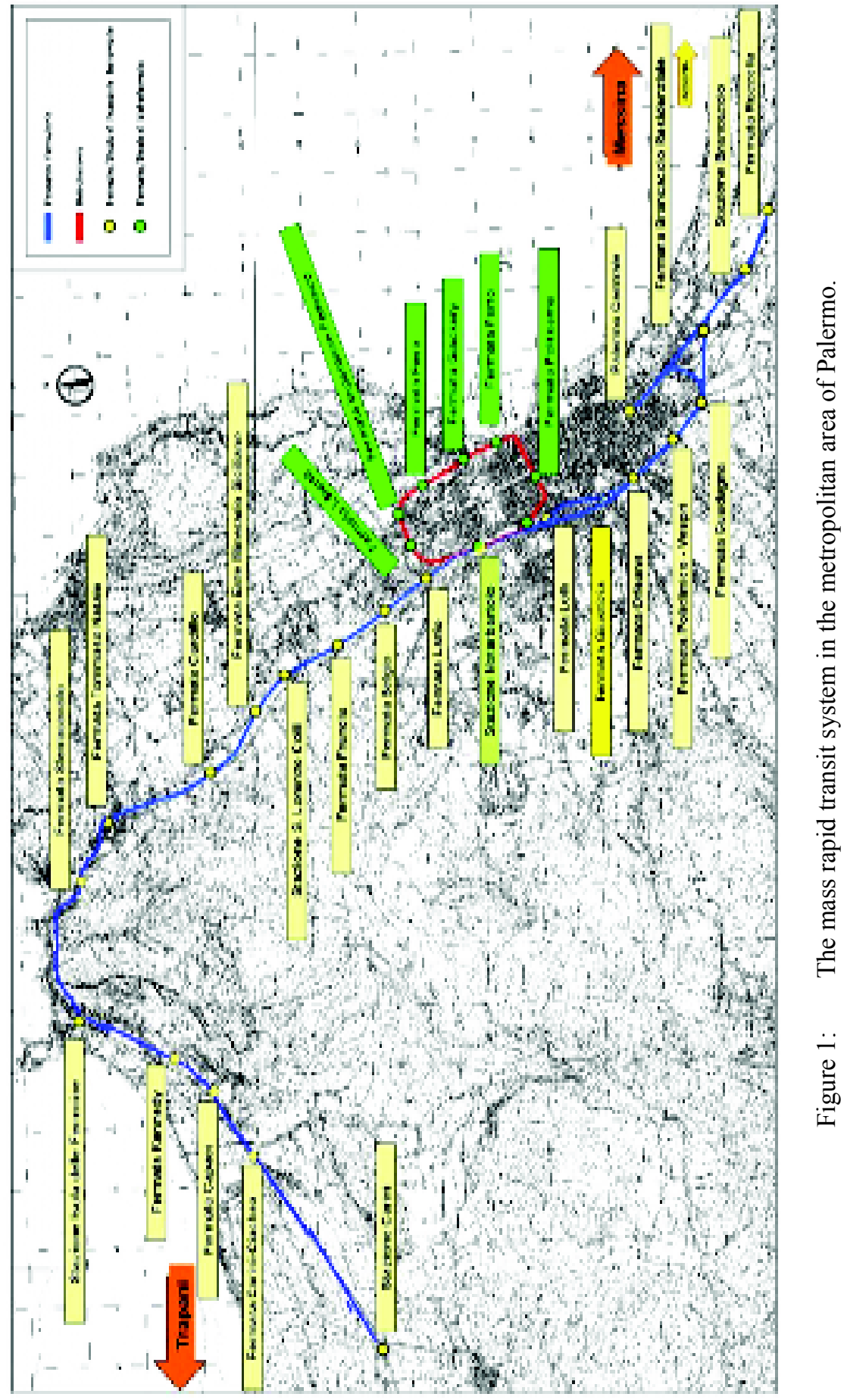




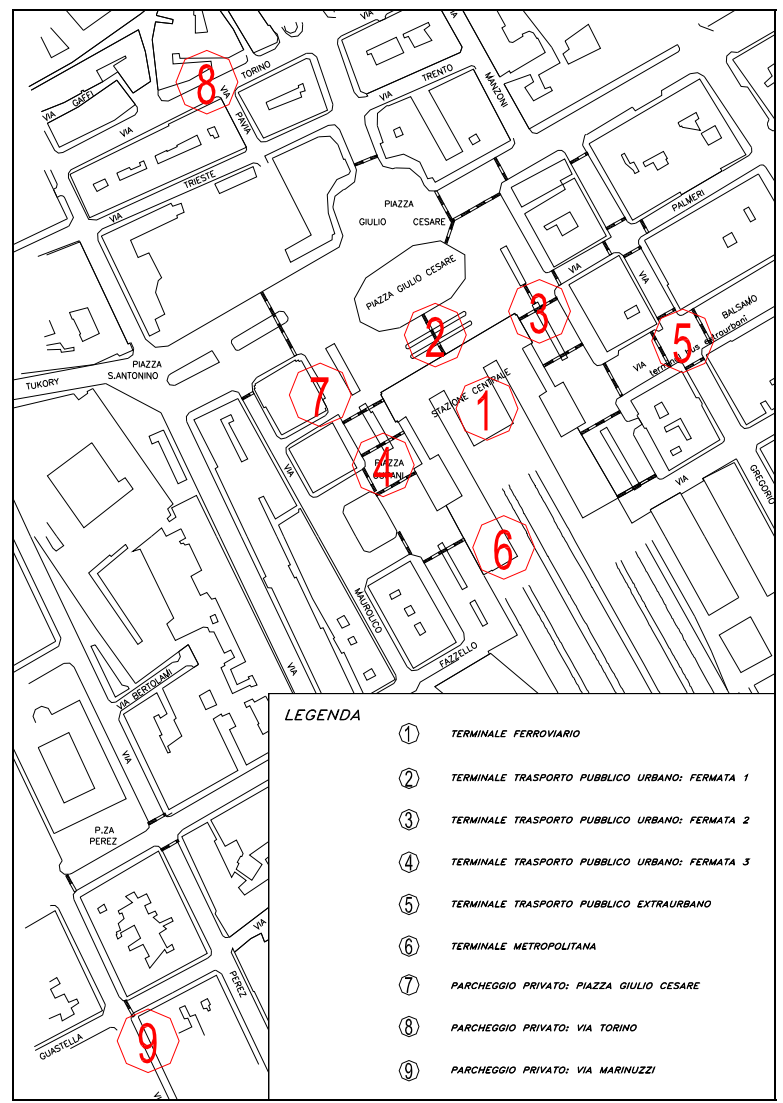

Figure 2: $\quad$ Terminals in the study area.

Table 1: $\quad$ Paths' lengths (expressed in m) among terminals.

\begin{tabular}{|c|c|c|c|c|c|c|c|c|c|}
\hline $\boldsymbol{O} / \boldsymbol{D}$ & $\mathbf{1}$ & $\mathbf{2}$ & $\mathbf{3}$ & $\mathbf{4}$ & $\mathbf{5}$ & $\mathbf{6}$ & $\mathbf{7}$ & $\boldsymbol{8}$ & $\mathbf{9}$ \\
\hline $\boldsymbol{1}$ & - & 37.69 & 56.54 & 53.44 & 154.92 & 35.47 & 90.09 & 289.46 & 513.65 \\
\hline $\mathbf{2}$ & 37.69 & - & - & - & 208.09 & 79.94 & 111.37 & 246.01 & 560.56 \\
\hline $\mathbf{3}$ & 56.54 & - & - & - & 137.68 & 97.03 & 142.22 & 318.01 & 590.98 \\
\hline $\mathbf{4}$ & 53.44 & - & - & - & 211.15 & 44.66 & 59.18 & 380.00 & 467.29 \\
\hline $\mathbf{5}$ & 154.92 & 208.09 & 137.68 & 211.15 & - & 158.00 & - & - & - \\
\hline $\mathbf{6}$ & 35.47 & 79.94 & 97.03 & 44.66 & 158.00 & - & 104.75 & 327.58 & 453.28 \\
\hline $\mathbf{7}$ & 90.09 & 111.37 & 142.22 & 59.18 & - & 104.75 & - & - & - \\
\hline $\boldsymbol{8}$ & 289.46 & 246.01 & 318.01 & 380.00 & - & 327.58 & - & - & - \\
\hline $\mathbf{9}$ & 513.65 & 560.56 & 590.98 & 467.29 & - & 453.28 & - & - & - \\
\hline
\end{tabular}

$$
\beta^{*}=\arg \min _{b \in S_{B}}\left[\sum_{i} \frac{\left(b_{i}-\bar{\beta}_{i}\right)^{2}}{\operatorname{var}\left[\sigma_{i}\right]}+\sum_{l} \frac{\left(\bar{f}_{o d}-\sum_{i} d_{o d m}\left(b_{i}\right)\right)^{2}}{\operatorname{var}\left[\varepsilon_{o d}\right]}\right]
$$

where: $b_{i}$ is the vector of coefficients; $\beta_{i}$ the initial condition vector coming from preliminary survey; $f_{\text {od }}$ the vector of observed flows; $d_{o d m}$ the vector of estimated flows in term of coefficients $b_{i} ; \sigma_{i}$ and $\varepsilon_{o d}$ the difference among vectors of 
Table 2: $\quad$ O/D matrix.

\begin{tabular}{|c|c|c|c|c|c|c|c|c|c|}
\hline $\boldsymbol{O} / \boldsymbol{D}$ & $\mathbf{1}$ & $\mathbf{2}$ & $\mathbf{3}$ & $\mathbf{4}$ & $\mathbf{5}$ & $\mathbf{6}$ & $\mathbf{7}$ & $\mathbf{8}$ & $\mathbf{9}$ \\
\hline $\mathbf{1}$ & - & 219 & 164 & 285 & 131 & 27 & 2 & 6 & 2 \\
\hline $\mathbf{2}$ & 117 & - & 0 & 0 & 22 & 30 & 1 & 4 & 0 \\
\hline $\mathbf{3}$ & 87 & 0 & - & 0 & 13 & 10 & 2 & 2 & 0 \\
\hline $\mathbf{4}$ & 152 & 0 & 0 & - & 18 & 7 & 2 & 3 & 1 \\
\hline $\mathbf{5}$ & 158 & 45 & 22 & 32 & - & 40 & 0 & 0 & 0 \\
\hline $\mathbf{6}$ & 18 & 42 & 14 & 11 & 43 & - & 2 & 4 & 1 \\
\hline 7 & 3 & 3 & 1 & 3 & 0 & 2 & - & 0 & 0 \\
\hline $\boldsymbol{8}$ & 5 & 3 & 3 & 1 & 0 & 2 & 0 & - & 0 \\
\hline $\mathbf{9}$ & 5 & 1 & 2 & 0 & 0 & 2 & 0 & 0 & - \\
\hline
\end{tabular}

coefficients and flows respectively; subjected to sign constrains on coefficients of model $b_{i}$ (for more details see Cascetta, [7]).

Attributes considered in this analysis were: walking running time $\boldsymbol{T P}$ (expressed in minutes), number of pedestrian crossings $\boldsymbol{N A}$, whole waiting time to cross the road $\boldsymbol{T A A}$ (expressed in minutes), ticketing waiting time $\boldsymbol{T B}$ (expressed in minutes), modal integration $\boldsymbol{I M}$, waiting time $\boldsymbol{T} \boldsymbol{A}$ (expressed in minutes). For any terminal, attributes related to the pedestrian path were estimated by:

- walking running time: assuming a mean speed of $1 \mathrm{~m} / \mathrm{s}$ and by knowledge length of path we can estimate the attribute;

- number of pedestrian crossings along the pedestrian path;

- whole waiting time to cross the road depends on type of road intersection (controlled, not controlled, on request, ....), i.e. a signalized intersection by HCM, (2000) as follows:

$$
t_{a}=\frac{0,5 *(C-V)^{2}}{C}
$$

$t_{a}$ average pedestrian delay (s)

$C$ is the cycle length (s)

$V \quad$ effective green time (for pedestrians) (s);

- ticketing waiting time: those pedestrian paths for which is necessary to buy a ticket, the waiting time was estimated by a direct measure;

- modal integration is a dummy variable that assumes values 1 if the considered path links two terminal for which there is fare integration; 0 otherwise;

- $\quad$ waiting time estimated direct measure, which can be caused by waiting time at bus stops, delays to departures and arrivals and parking search time.

Wholly, we calibrated nine distribution models for each terminal situated in the study area.

For instance for the terminal 1 we have achieved coefficients of model and the goodness of fit between measured and estimated values by determination coefficient and Root Mean Square Error (table 3 and figure 3). 


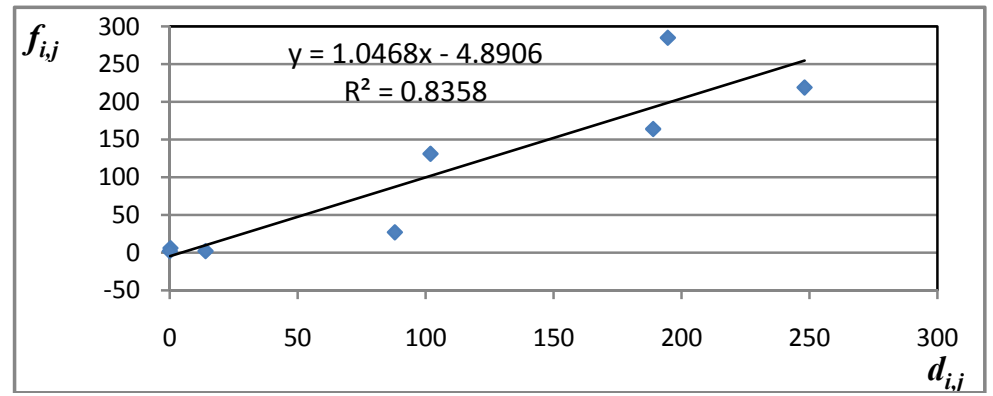

Figure 3: $\quad$ Measured pedestrian flows $\left(f_{i j}\right)$ versus estimated flows $\left(d_{i j}\right)$, terminal 1.

Table 3: $\quad$ Coefficients of the calibrated model related terminal 1.

\begin{tabular}{|c|c|c|c|c|c|}
\hline $\mathbf{O}$ & $\mathbf{D}$ & $\boldsymbol{f}_{\boldsymbol{i}, \boldsymbol{j}}$ & $\boldsymbol{V}_{\boldsymbol{i j}}$ & $\boldsymbol{d}_{\boldsymbol{o d}}(\boldsymbol{b})_{\boldsymbol{i}, \boldsymbol{j}}$ & $\boldsymbol{\varepsilon}$ \\
\hline 1 & 2 & 219 & -2.95 & 248 & 29 \\
\hline 1 & 3 & 164 & -3.22 & 189 & 25 \\
\hline 1 & 4 & 285 & -3.19 & 195 & -90 \\
\hline 1 & 5 & 131 & -3.84 & 102 & -29 \\
\hline 1 & 6 & 27 & -3.98 & 88 & 61 \\
\hline 1 & 7 & 2 & -5.82 & 14 & 12 \\
\hline 1 & 8 & 6 & -9.54 & 0 & -6 \\
\hline 1 & 9 & 2 & -11.43 & 0 & -2 \\
\hline
\end{tabular}

\begin{tabular}{|c|c|c|c|}
\hline $\boldsymbol{\beta}_{T P}$ & -0.75 & $b_{1}$ & -0.92 \\
\hline$\beta_{N A}$ & -0.15 & $b_{2}$ & -0.21 \\
\hline $\boldsymbol{\beta}_{T A A}$ & -0.2 & $b_{3}$ & -0.32 \\
\hline $\boldsymbol{\beta}_{T A}$ & -1.3 & $b_{4}$ & -0.13 \\
\hline $\boldsymbol{\beta}_{T B}$ & -0.37 & $b_{5}$ & -0.09 \\
\hline $\boldsymbol{\beta}_{I M}$ & 0.35 & $b_{6}$ & 0.28 \\
\hline$\beta_{A S A 1}$ & 0.5 & $\boldsymbol{b}_{7}$ & 1.34 \\
\hline$\beta_{A S A 2}$ & 0.25 & $\boldsymbol{b}_{8}$ & 1.36 \\
\hline$\beta_{A S A 3}$ & 0.5 & $b_{9}$ & 1.34 \\
\hline$\beta_{A S A 4}$ & 0.25 & $b_{10}$ & 1.89 \\
\hline$\beta_{A S A S}$ & 0.55 & $b_{11}$ & -1.12 \\
\hline$\beta_{A S A 6}$ & 0.35 & $b_{12}$ & -1.86 \\
\hline$p_{A S A}$ & 0.75 & $b_{13}$ & -0.82 \\
\hline
\end{tabular}

Table 4: $\quad$ Goodness of fit for calibrated models.

\begin{tabular}{|c|c|c|c|c|c|c|c|c|c|}
\hline & $\boldsymbol{T 1}$ & $\boldsymbol{T 2}$ & $\boldsymbol{T 3}$ & $\boldsymbol{T 4}$ & $\boldsymbol{T 5}$ & $\boldsymbol{T 6}$ & $\boldsymbol{T 7}$ & $\boldsymbol{T} \boldsymbol{8}$ & $\boldsymbol{T} \boldsymbol{9}$ \\
\hline $\mathbf{R}^{2}$ & 0.835 & 0.927 & 0.735 & 0.671 & 0.942 & 0.930 & 0.197 & 0.000 & 0.024 \\
\hline RMSE & 42.39 & 14.80 & 17.46 & 36.42 & 33.64 & 4.17 & 1.67 & 2.22 & 1.86 \\
\hline
\end{tabular}

$$
R M S E_{k}=\sqrt{\frac{1}{N} \sum_{j=1}^{N}\left(f_{i j}-d_{i j}\right)^{2}}
$$

Table 4 summarizes the goodness of fit for nine calibrated models. It should be noted that, calibrated models for terminals $7,8,9$ do not provide a good estimation; since very few people use parking areas 7, 8, 9 due to long distances 
and high parking fares, which disincentive the use of parking for changing transport mode. Wholly, the private parking supply is about 500 places with a parking fare between 1 and $2.5 € / \mathrm{h}$.

Figures 4, 5, 6 show the choice probability of paths having origin node the terminal 1, 2 and 3 in term of the waiting time, the number of pedestrian crossings and the walking running time respectively.

These figures highlights the high influence of the waiting time, the number of pedestrian crossings and the walking running time on choice of walking paths.

Furthermore the user satisfaction was determined on paths related to calibrated models in the study area analysed (whose characteristics are known), as follows:

$$
s(V)_{k}=\theta \ln \sum_{j} \exp \left(V_{i j} / \theta\right)
$$

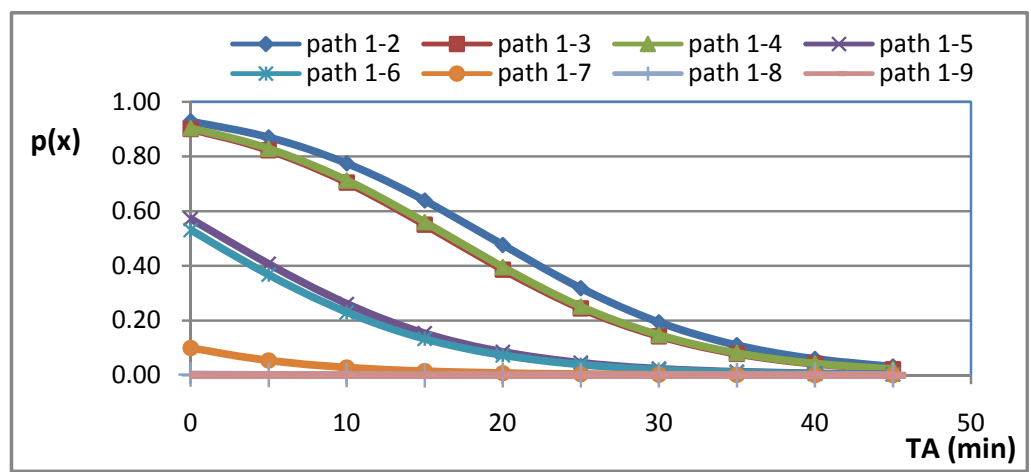

Figure 4: Choice probability of a single path in terms of waiting time.

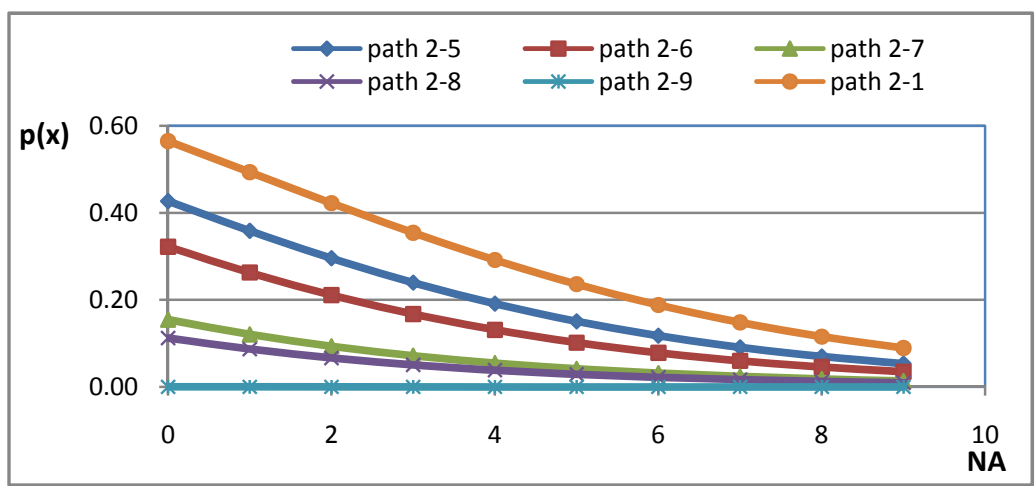

Figure 5: Choice probability in terms of number of pedestrian crossings. 


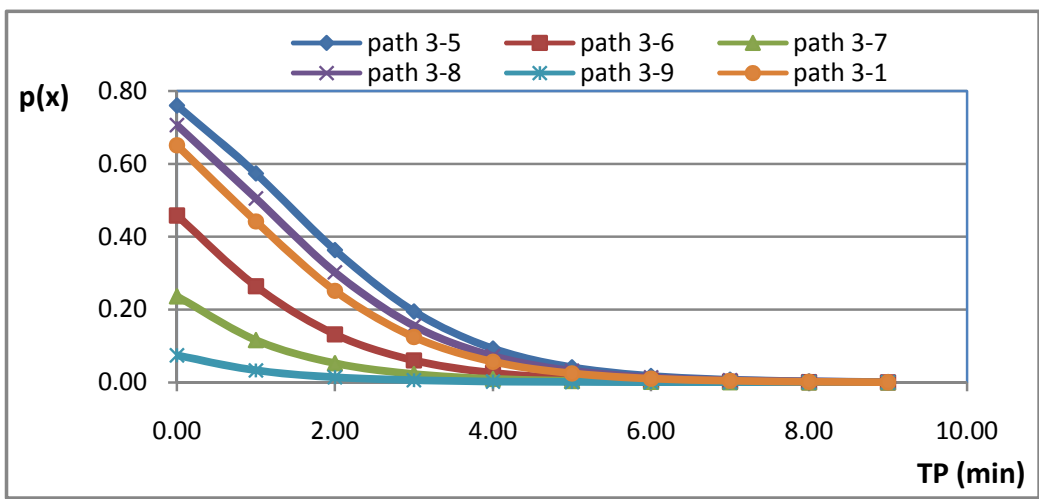

Figure 6: Probability in terms of walking/running time.

\section{Results}

Once the mobility of the interchange node has been analyzed, nine discrete choice models have been calibrated and conflict points and bottle necks within the study area have been identified, we have proposed some different integrative measures to improve the transfer mobility safety within the node. Some improving measures can be:

- zebra-striped crossings at unsignalized intersections;

- traffic lights activated by pedestrians;

- pedestrian islands for crossing large roads;

- traffic calming measures.

Moreover we have identified some interventions aiming to improve transfer mobility quality able to incentive modal split reducing disutility related to terminal transfer by design of two scenarios. Some of these measures concern directly the interchange node quality (endogenous intervention measures); others (exogenous intervention measures) concern even the interchange node, but as part of a wider integrated multimodal transport system. In such context we have chosen to divide intervention measures in:

- endogenous

1 zebra-striped crossings at an unsignalized intersection;

2 reduction of waiting time at the signalized intersections (by cycle time reduction);

3 employment of three automated people movers (APM) close to the railway station;

4 increase of ticket office number and e-ticket kiosks;

5 reserved lanes for urban and regional bus service within the study area;

6 free bus shuttle service to connect main terminal (railway station and metro) with private parking areas; 
- exogenous

1 Increase of the urban bus service frequency.

These intervention measures allow one to improve transfer pedestrian mobility of the interchange node reducing the perceived disutility of users. In particular, such measures influence directly some attributes as such as: the walking running time, whole waiting time to cross the road, the ticketing waiting time and the waiting time. Figure 7 and 8 shows the route of bus shuttle service and automated people movers.

The first scenario has been built taken into account only endogenous intervention measures, whereas the second has been designed considering also the improvement of the urban bus service frequency. These two scenarios have been compared with the actual scenario, which has been previously described.

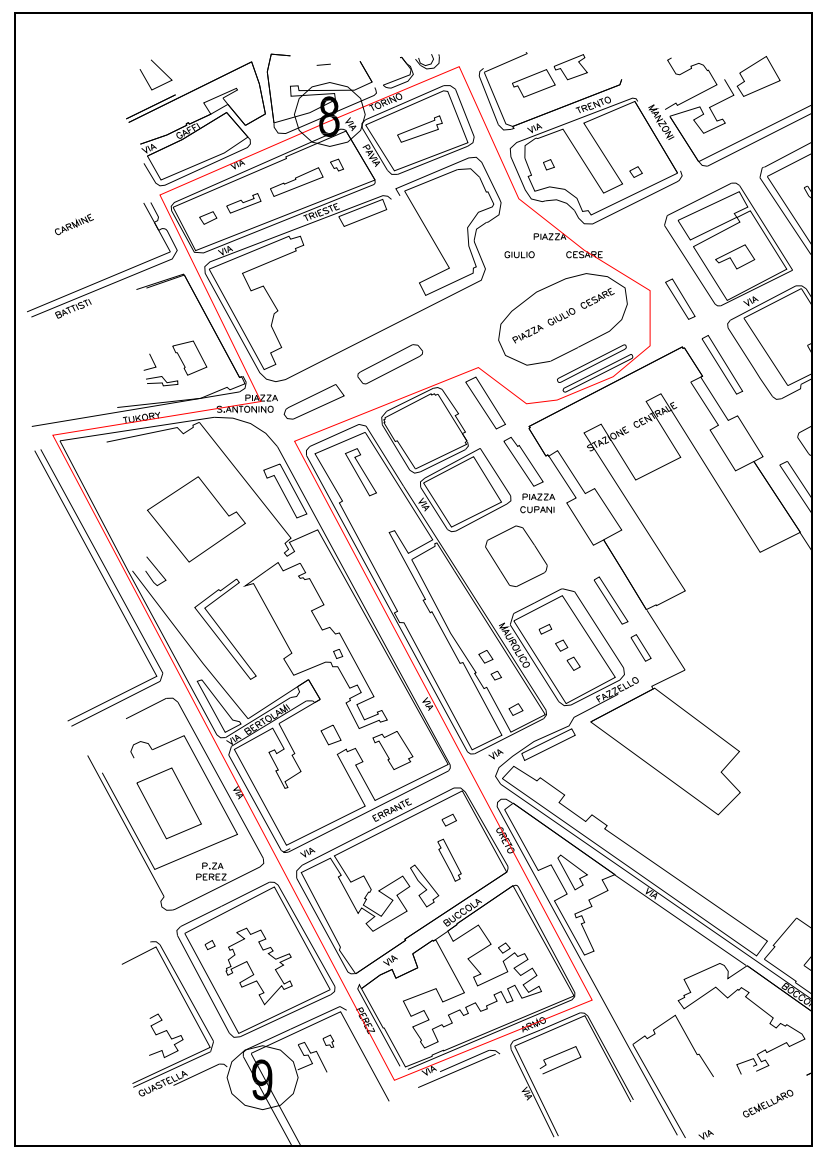

Figure 7: The route of the bus shuttle service. 


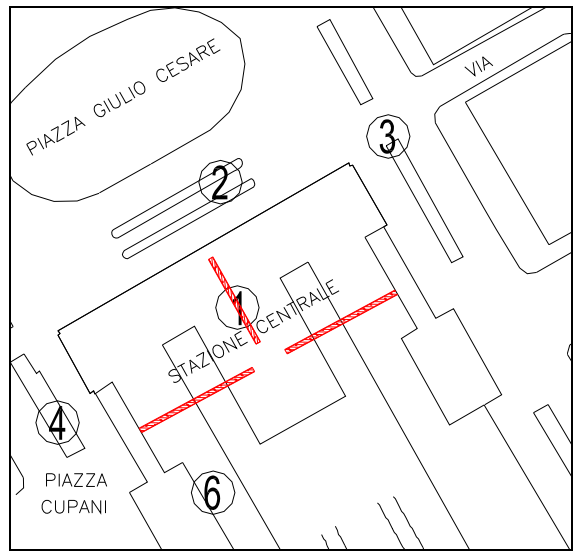

Figure 8: $\quad$ Automated people movers.

Table 5: $\quad$ Percentage variation of utility function.

\begin{tabular}{|c|c|c|c|}
\hline \multicolumn{4}{|c|}{$\begin{array}{c}\text { Percentage Variations of Utility Function } \\
{[\%]}\end{array}$} \\
\hline $\mathbf{O}$ & $\mathbf{D}$ & Scenario 1 & Scenario 2 \\
\hline 1 & 2 & 5.93 & 23.23 \\
\hline 1 & 3 & 13.56 & 28.80 \\
\hline 1 & 4 & 11.10 & 26.65 \\
\hline 1 & 5 & 10.16 & 10.16 \\
\hline 1 & 6 & 0.00 & 0.00 \\
\hline 1 & 7 & 14.63 & 14.63 \\
\hline 1 & 8 & 86.47 & 86.47 \\
\hline 1 & 9 & 37.95 & 37.95 \\
\hline
\end{tabular}

Table 6: $\quad$ Variation of user satisfaction.

\begin{tabular}{|c|c|c|c|}
\hline \multicolumn{4}{|c|}{ User Satisfaction Level } \\
\hline Model & Actual Scenario & First Scenario & Second Scenario \\
\hline$S(V)_{1}$ & -0.03 & 0.42 & 0.52 \\
\hline$S(V)_{2}$ & 0.48 & 1.36 & 1.35 \\
\hline$S(V)_{3}$ & 0.36 & 0.78 & 0.78 \\
\hline$S(V)_{4}$ & 0.75 & 1.03 & 1.02 \\
\hline$S(V)_{5}$ & -0.53 & -0.42 & -0.41 \\
\hline$S(V)_{6}$ & 0.40 & 1.19 & 1.34 \\
\hline$S(V)_{7}$ & 0.07 & 0.09 & 0.09 \\
\hline$S(V)_{8}$ & -0.48 & -0.26 & -0.25 \\
\hline$S(V)_{9}$ & -2.03 & -1.02 & -0.93 \\
\hline
\end{tabular}

Table 5 shows percentage variations of utility function related to paths of terminal 1 for two scenarios. Whereas whole results are summarized in table 6 , that highlights the user satisfaction levels for actual, first and second scenario. For sake of notice, whether all intervention measures were adopted, user satisfaction levels would improve the perceived quality of the modal interchange node. 


\section{Conclusion}

The paper presents an approach to re-design a passenger interchange node by random utility models. We calibrated nine discrete choice models taking into account attributes able to explain the passenger behaviour by observed flows and generalized least squares technique.

The analysis highlighted which attributes and have a great influence on the passenger behaviour as the waiting time, the number of pedestrian crossings and the walking running time.

Furthermore an ex ante / ex post analysis was carried out in order to design and evaluate measure to incentive modal integration improving perceived quality and transfer facility in walking path. Therefore, the user satisfaction level was determined on paths related to calibrated models in the study area analysed. Results of the analysis highlight as the developed methodology by calibrated model is a good decision support system to appraise measures that the designer can adopt to reduce transfer disutility of passengers.

\section{References}

[1] Delle Site P., Epifani C., Filippi F. (1992), "A method for the optimal location, selection and sizing of short-distance transport facilities", $I^{\text {th }}$ Meeting of the Euro Working Group on Urban Traffic and Transportation, Landshut.

[2] Parizi M. S. \& Braaksma J. P. (1995), “An optimum re source utilization plan for airport terminal buildings", Transportation Research Record 1506, Washington.

[3] De Barros A. G. \& Wirasinghe S. C. (2002), "Optimal terminal configurations for new large aircraft operations", Transportation Research Part A, Elsevier.

[4] Correira A. R., Wirasinghe S. C. \& de Barros A. G. (2008), "A global index for level of service evaluation at airport passenger terminals", Transportation Research Part E, Elsevier.

[5] De Barros A. G., Somasundaraswaran A. K. \& Wirasinghe S. C. (2007), "Evaluation of level of service for transfer passengers at airports", Journal of Air Transport Management, Elsevier.

[6] Correira A. R., Wirasinghe S. C. \& de Barros A. G. (2008), "Overall level of service measures for airport passenger terminals", Transportation Research Part A, Elsevier.

[7] Cascetta E. (1998) "Teoria e metodi dell'ingegneria dei sistemi di trasporto", UTET, Torino 